\title{
Investigating natural drivers of vegetation coverage variation using MODIS imagery in Qinghai, China
}

\author{
ZHOU Lei ${ }^{1}$, LYU Aifeng ${ }^{2 *}$ \\ ${ }^{1}$ China National Environmental Monitoring Center, Beijing 100012, China; \\ ${ }^{2}$ Key Laboratory of Water Cycle and Related Land Surface Processes, Institute of Geographic Sciences and Natural Resources \\ Research, Chinese Academy of Sciences, Beijing 100101, China
}

Abstract: The climatically sensitive Qinghai province of China has been recognized as a hotspot for studies on the feedbacks of terrestrial ecosystems to global climate change. Thus, investigating vegetation coverage and its natural drivers in Qinghai is an important focus of ecosystem research. On the basis of Moderate Resolution Imaging Spectroradiometer (MODIS) Enhanced Vegetation Index (EVI) time series data, we estimated the vegetation coverage in this region using the dimidiate pixel model. Trend analyses, correlations between meteorological parameters, changes in vegetation coverage, and the temporal and spatial relationships between soil texture and vegetation coverage were used to investigate the possible drivers of vegetation coverage variations. The results indicated that the reduction of vegetation coverage slowed down in the period from 2000 to 2012. Annual mean temperature was the main climatic driver of the total extremely low and low vegetation coverage areas in Qinghai, followed by the precipitation anomalies. The extremely low and low vegetation coverage areas were mainly distributed in regions with a mean annual relative air humidity of $<40 \%$ and the spatial distributions of these two area types differentiated along the $200-\mathrm{mm}$ rainfall contours. The total extremely low and low vegetation coverage areas were mainly characterized by sandy clay loam soil, followed by loamy sand and sandy soil. Regions with sandy loam or loam soil have the greatest risk of vegetation coverage reductions. Knowledge of vegetation coverage variation and its natural drivers in the ecologically fragile region of Qinghai can provide scientific support for managing environmental change and desertification.

Keywords: vegetation coverage; remote sensing; MODIS; climate change

Citation: ZHOU Lei, LYU Aifeng. 2016. Investigating natural drivers of vegetation coverage variation using MODIS imagery in Qinghai, China. Journal of Arid Land, 8(1): 109-124. doi: 10.1007/s40333-015-0016-1

Vegetation is the natural link between the soil, atmosphere and water in an environment (Pan et al., 2015). Plants play an important role in the energy exchange, biogeochemical cycles and hydrological cycles in terrestrial systems and are an indicator of global change (Sun et al., 1998). Vegetation coverage is also an important indicator of the growth trends of vegetation communities and provides essential information for describing ecological systems. There is a close relationship between vegetation coverage and climatic factors. Global climate change has an amplified effect the Qinghai-Tibet Plateau, and the headwater region in this area is more sensitive to climate change. Thus, the investigation of vegetation coverage and its natural drivers in Qinghai is important for understanding climate change (Peng et al., 2012; Guo et al., 2014). Researching the changes in annual vegetation coverage and its natural drivers has great theoretical and practical significance for assessments of terrestrial ecosystems and environmental management (Mu et al., 2012).

\footnotetext{
*Corresponding author: LYU Aifeng (E-mail: lvaf@163.com)

Received: 2015-02-12; revised 2015-07-29; accepted: 2015-08-06

(C) Xinjiang Institute of Ecology and Geography, Chinese Academy of Sciences, Science Press and Springer-Verlag Berlin Heidelberg 2016
} 
Many unfavorable factors (e.g. strong wind, drought, salinity and freeze-thaw cycles) increase the risk of vegetation coverage reductions in Qinghai (Yu et al., 2007). The use of remote sensing imagery has enabled a better understanding of the dynamics of the current vegetation coverage in this region (Huang et al., 2009; Yan et al., 2009). For example, satellite images of vegetation coverage have been used for assessing temporal vegetation dynamics (Qi et al., 2012). Highresolution and multi-spectral images can be acquired over several years to analyze regional changes in landform and land degradation (Runnström, 2003; Yan et al., 2007). This technology has become a valuable tool for monitoring and evaluating regional and global variations in vegetation coverage (Liberti et al., 2009).

Climatic variation is commonly considered as a key factor driving vegetation change (Wang et al., 2004), as climate determines the distribution of vegetation, which in turn influences the surface energy flux and water balance. The disrupted surface energy flux and water balance subsequently reduce precipitation, further preventing the re-establishment of vegetation (Bonan, 2002). In recent years, the inter-relationship between climate and vegetation has been closely examined via remote sensing and direct field observations (Taylor et al., 1997; Taylor and Lebel, 1998; Kim and Byun, 2009). Many studies have found that natural factors (e.g. climatic variations and soil properties) significantly influence vegetation coverage (Peng et al., 2012; Wang et al., 2012; Qin et al., 2015). Moreover, some studies have revealed that human activities can affect vegetation coverage as well (Hou et al., 2015).

Changes in the global and regional patterns of precipitation, temperature, wind speed and relative air humidity have historically led to the expansion and contraction of major deserts (D’Odorico et al., 2013). Many of these deserts were formed millions of years ago, and most of them expanded as a result of Pleistocene climate change (Goudie, 2006). Increased drought and overall global climate change since the $20^{\text {th }}$ Century (Sheffield et al., 2009) have resulted in uneven spatial and seasonal precipitation distributions (Burke et al., 2006; IPCC, 2007; Dai, 2011). Simulations based on various climate models suggested that Western Asia will experience an overall reduction in mean precipitation by the end of the $21^{\text {st }}$ Century (Zhang et al., 2007). However, our understanding of the relationship between climate change and vegetation coverage is limited. In fact, vegetation coverage is influenced by complex factors including biophysical and human influences, which may vary over a wide range of spatial and temporal scales, and quantifying these factors is extremely challenging (MEA, 2005). In addition, soil texture (and thus water-holding capacity) is another important factor for determining the extent of the desertification (USDA, 2008). Vegetation coverage varies with soil texture even under the same climate. Changes in soil texture and loss of water-holding capacity may result from the erosion of fine soil (D’Odorico et al., 2007).

Although there have been remarkable advances in research on vegetation coverage variations in China over the past several decades, many of these processes are still not well understood. Therefore, the aims of this study were to: (1) conduct an analysis of the temporal and spatial dynamics of vegetation coverage and climate characteristics in Qinghai; (2) identify the main climatic factors that drive variations in vegetation coverage; and (3) examine soil texture and its spatial relationship with vegetation coverage. The results will improve our understanding of the processes driving vegetation coverage variations.

\section{Study area and data collection}

\subsection{Study area}

Qinghai province is located in Northwest China and consists of a range of topographies, though more than four-fifths consists of plateau areas. Qinghai is divided into the Qilian Mountains, Qaidam Basin and southern Qinghai Plateau regions (Fig. 1), and its average elevation is greater than $3,000 \mathrm{~m}$.

Qinghai is characterized by a plateau continental climate, with low temperatures, large day-night temperature fluctuations, concentrated rain events, numerous cloud-free days and strong solar 


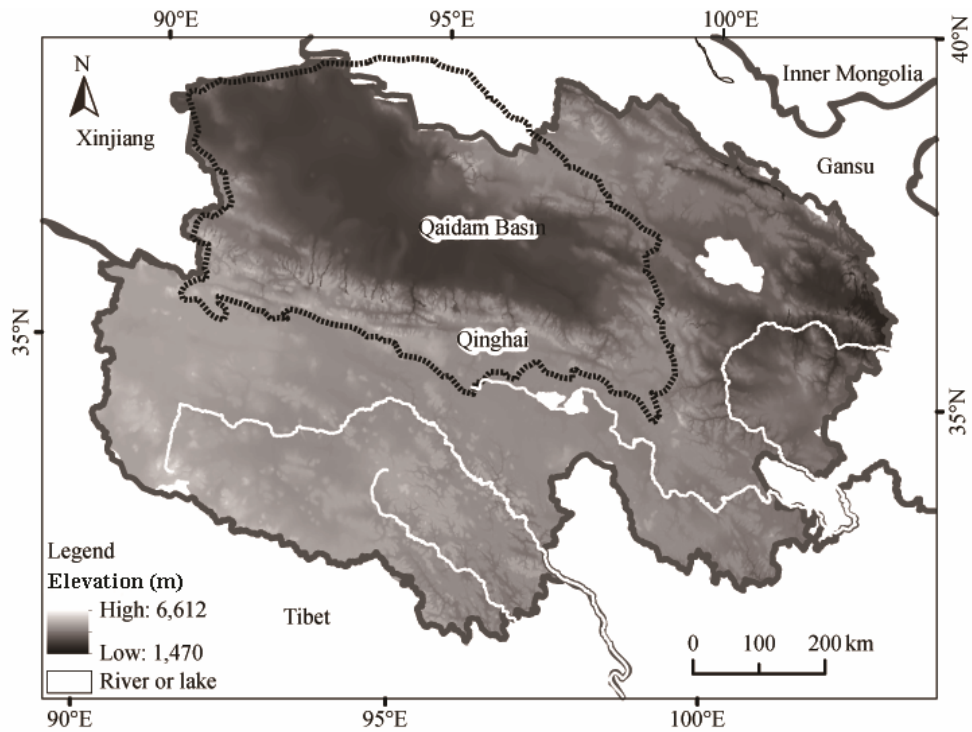

Fig. 1 Location and topography of Qinghai province

radiation (Fig. 2). However, within this province, there are significant differences in regional climates. For example, the annual mean temperature in the Huangshui valley in East Qinghai ranges from $2^{\circ} \mathrm{C}$ to $9^{\circ} \mathrm{C}$, the frost-free period is $100-200$ days, and $250-550 \mathrm{~mm}$ of precipitation is concentrated in July to September. In contrast, in the Qaidam Basin, the annual mean air temperature ranges from $2^{\circ} \mathrm{C}$ to $5^{\circ} \mathrm{C}$ (Fig. 2b), the annual precipitation is approximately $200 \mathrm{~mm}$ (Fig. 2c), and there are more than 3,000 h of sunshine. The temperature in the northwestern high mountains and southern Qinghai plateau is $8^{\circ} \mathrm{C}$ lower than that in the Qaidam Basin, and the annual precipitation ranges from 100 to $500 \mathrm{~mm}$, with the exception of the Qilian Mountains, Altun Mountains, and mountains in the western river region.

\subsection{Data}

\subsubsection{Remote sensing data}

Moderate Resolution Imaging Spectroradiometer (MODIS) data from Earth Observation System (EOS) satellites used in this study included enhanced vegetation index (EVI) products (MOD13A2, Vegetation Indices 16-Day L3 Global $1 \mathrm{~km}$ ) with a 16-day interval from 2000 to 2012 and yearly land cover from 2001 to 2012 (MCD12Q1, MODIS Terra+Aqua Land Cover Type Yearly L3 Global $500 \mathrm{~m}$ SIN Grid). The EVI data were retrieved from daily, atmosphere-corrected, bidirectional surface reflectance measurements. We processed the EVI data with a MODIS-specific compositing method based on product quality assurance metrics to remove low quality pixels. The land cover data with a 500-m spatial resolution were resampled with a 1-km spatial resolution (Friedl et al., 2002, 2010). All the EVI and land cover data were derived from the Level 1 and Atmosphere Archive and Distribution System (http://ladsweb.nascom.nasa.gov/data/search.html). Both the MOD13A2 and MCD12Q1 data were preprocessed (e.g., atmospheric, geometric, and radiometric corrections) by the National Aeronautics and Space Administration (NASA) prior to being used.

\subsubsection{Meteorological data}

China's annual terrestrial climate dataset (1961-2012) was provided by the China Meteorological Data Sharing Service System. The annual precipitation, mean wind speed, mean air temperature and mean relative air humidity data were collected from 39 stations in Qinghai. The data acquisition was in strict accordance with the Ground Surface Meteorological Observation Protocols (CMB, 2003), and the data were quality controlled using China's ground monthly climate information files. All climatic data passed a rigorous system of checks, including 

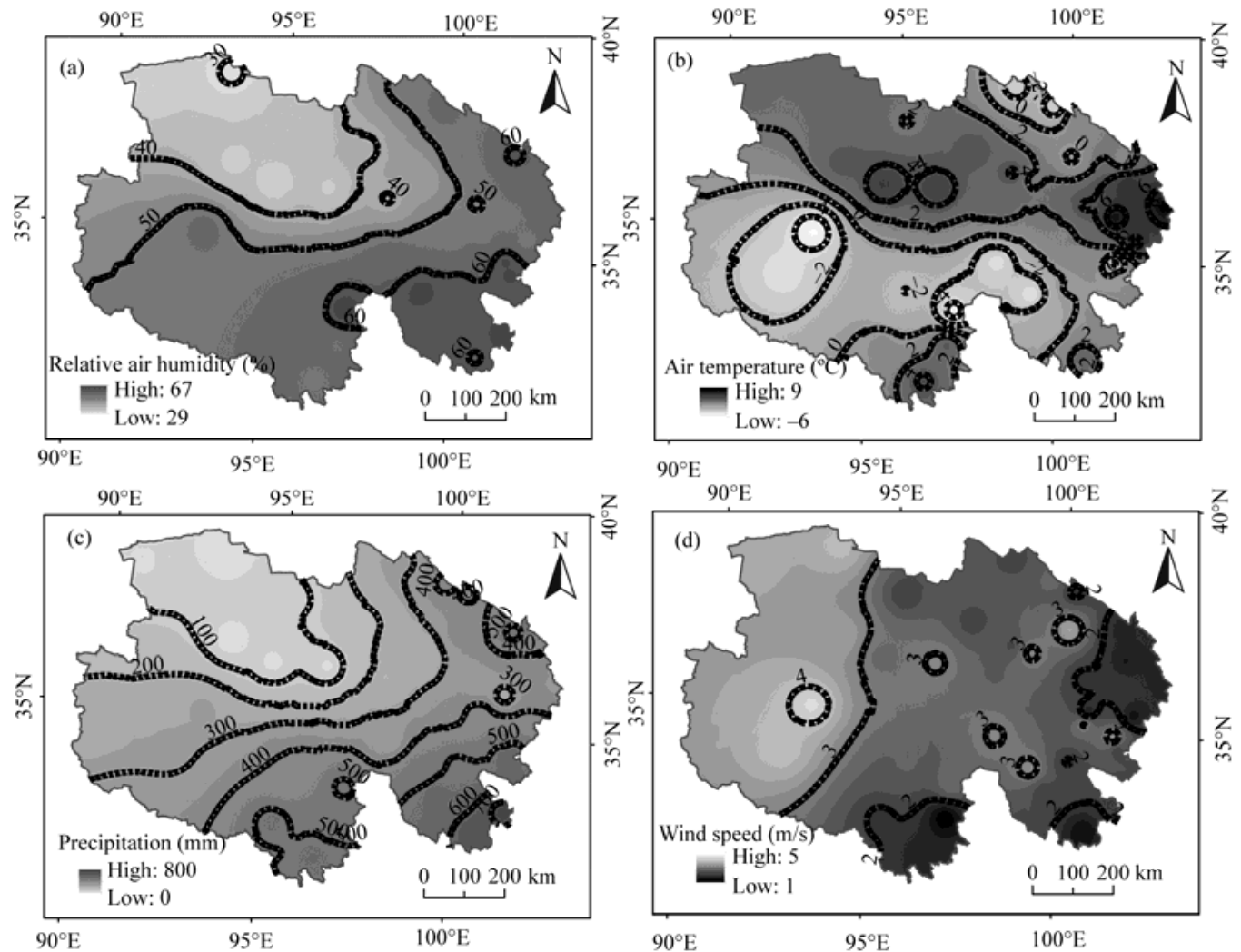

Fig. 2 Spatially interpolated climate maps of Qinghai province. The Inverse Distance Weighted (IDW) interpolation method was used to generate the climate raster and contour maps. (a) multi-year mean relative air humidity; (b) multi-year mean air temperature; (c) multi-year mean precipitation; (d) Multi-year mean wind speed.

a time consistency check. The mean annual precipitation, annual mean wind speed, annual mean air temperature and annual mean relative air humidity from all weather stations in Qinghai from 2000 to 2012 were calculated. The average multi-year climatic data from each meteorological station from 1961 to 2012 were calculated and interpolated to raster images in Qinghai with a 1-km spatial resolution. Contours of climatic parameters were also constructed.

\subsubsection{Soil data}

Soil data (1-km spatial resolution) were taken from the Harmonized World Soil Database (HWSD), which were constructed by the Food and Agriculture Organization of the United Nations (FAO) and the International Institute for Applied Systems Analysis (IIASA, version 1.1). The Institute of Soil Science, Chinese Academy of Sciences provided 1:10,000 soil data for China. The soil data were formatted as a grid with a WGS84 projection and classified using the FAO-90 soil classification system (Fig. 3).

\section{Methodology}

\subsection{Dimidiate pixel model for remote sensing vegetation coverage inversions}

The MODIS EVI is a continuation of the Normalized Difference Vegetation Index (NDVI) and has significant improvements over the vegetation index formula and synthesis method. The EVI reduces interference from atmospheric noise, soil background influences and NDVI saturation over high vegetation coverage areas (Wang et al., 2006). Compared with NDVI time series, EVI time series have more pronounced seasonal characteristics and can better reflect seasonal variations in vegetation coverage. Therefore, the EVI provides useful information for assessing seasonal 


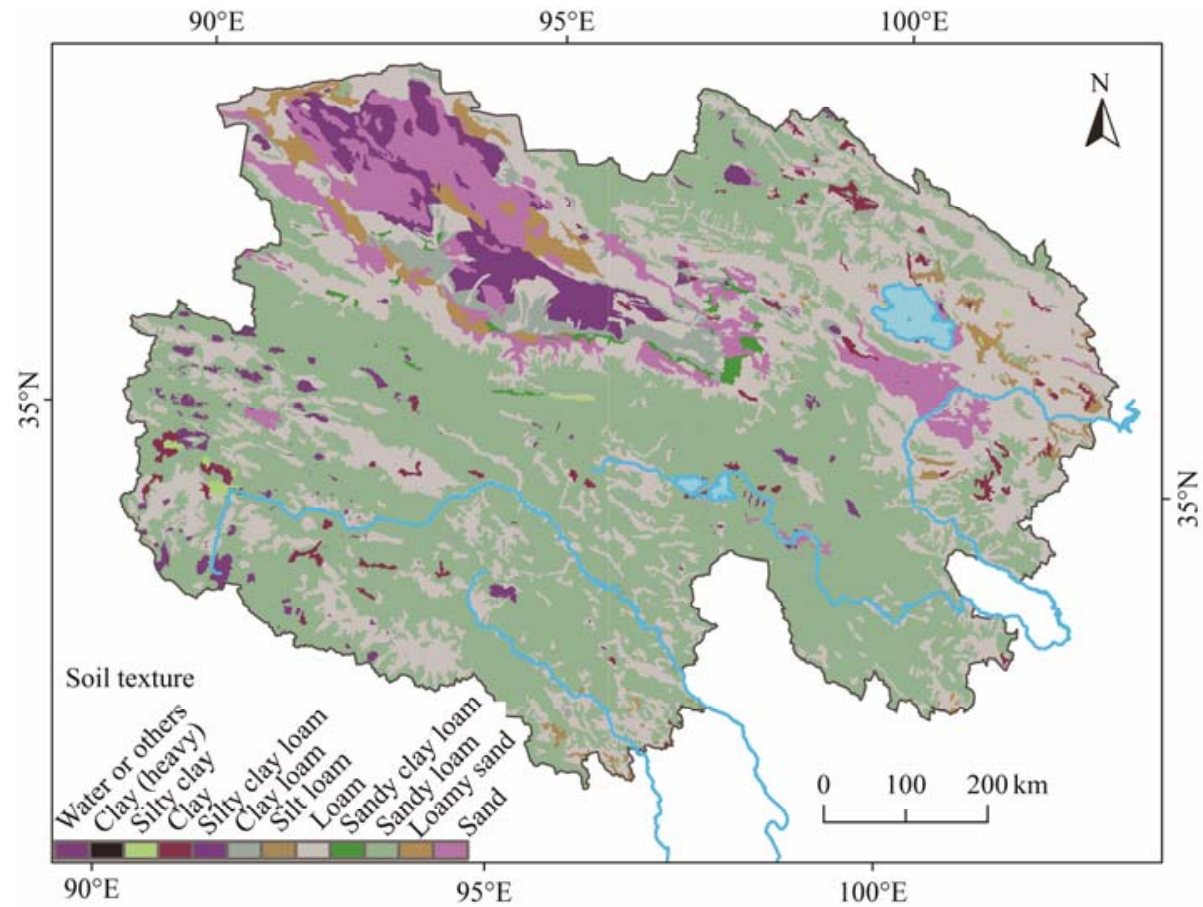

Fig. 3 Soil texture distribution in Qinghai province

vegetation coverage variations. We used the dimidiate pixel model to extract vegetation coverage inversions based on the EVI, after which vegetation coverage was used as a classification index for vegetation conditions from 2000 to 2012.

The principle of the dimidiate pixel model assumes that the reflectivity of each pixel can be divided into two parts. The reflectance values of each pixel can be defined as the weighted sum of the pure-vegetation pixel (land pixels excluding water, building and snow cover) and pure-soil pixel (non-vegetated) fractions (Maas, 1998):

$$
R=R_{v}+R_{s} .
$$

Where $R$ is the reflectivity of one pixel, $R_{v}$ is the reflectivity of the vegetative fraction of the pixels, and $R_{S}$ is the reflectivity of the soil fraction of the pixels.

Assuming the vegetation coverage of one pixel is a fraction of the vegetation coverage area $\left(f_{c}\right)$, then the ratio of the non-vegetated area to the total pixel area is $1-f_{c}$. Therefore, the reflectivity of mixed pixels can be expressed as $R=f_{c} \times R_{v}+\left(1-f_{c}\right) \times R_{s}$ (Zeng et al., 2000). According to the above principle, the EVI can be approximately expressed as $E_{E V I}=f_{c} \times E_{E V I v e g}+\left(1-f_{c}\right) \times E_{E V I s o i l}$, where $E_{E V I}$, $E_{E V I v e g}$, and $E_{E V I s o i l}$ are the EVI values at any pixel, pure-bare pixels and pure-vegetation pixels, respectively (Gutman and Ignatov, 1998; Qi et al., 2000).

Therefore, the vegetation coverage can be obtained using the following equation for a specific study area:

$$
f_{c}=\left(E V I-E_{\text {soil }}\right) /\left(E V I_{\text {veg }}-E V I_{\text {soil }}\right) \text {. }
$$

Where $f_{c}$ is the vegetation coverage, $E V I$ is the value of bare-land pixels, $E V I_{\text {soil }}$ is the minimum EVI value in the study area, and $E V I_{\text {veg }}$ is the maximum EVI value of full vegetation cover pixels in the study area. We identified the pure-land pixels based on the land types, the maximum and minimum EVI values were extracted from these pixels.

When using the dimidiate pixel model to estimate vegetation coverage, it is critical to accurately obtain the bare and completely vegetated pixels in the study area. Complex land cover types (e.g. water bodies, buildings and snow cover) will influence the maximum and minimum EVI values. In this study, the MODIS land cover product was used to exclude water bodies, buildings and snow- 
covered regions, and only land area was extracted to determine the maximum and minimum EVI values for estimating vegetation coverage. The MODIS land cover products were during the period of 2001 to 2012, and the study period covered the same time period. As the land cover changed little in 2000, land cover data from 2001 were used to represent land cover in both 2000 and 2001.

Many studies of remote sensing vegetation coverage have referred to technical specifications or made appropriate improvements depending on the study areas in China. In this study, we comprehensively referred to the remote sensing vegetation coverage classification criteria from studies in similar areas in the Fourth China National Desertification and Sandification Technical Specifications (Ding et al., 2004; He and He, 2011). The vegetation coverage was subsequently divided into five categories: (1) very high, (2) high, (3) moderate, (4) low and (5) extremely low (Table 1).

Table 1 Classification of vegetation coverage in Qinghai province

\begin{tabular}{|c|c|c|}
\hline Grade & Description & $\begin{array}{c}\text { Vegetation coverage } \\
(\%)\end{array}$ \\
\hline Very high & Land surface is covered by vegetation. & $>70$ \\
\hline High & $\begin{array}{l}\text { Land surface is mainly covered by vegetation. Dunes and sand } \\
\text { sheets are scattered, accounting for } 20 \% \text { or less of the total area. }\end{array}$ & $70-50$ \\
\hline Moderate & $\begin{array}{l}\text { Quicksand areas account for } 20 \%-40 \% \text { of the total area, and } \\
\text { vegetation cannot completely prevent sand drift. }\end{array}$ & $50-30$ \\
\hline Low & $\begin{array}{l}\text { Land productivity is basically lost; the whole desertification } \\
\text { area is in a semi-mobile state; and quicksand or Gobi account } \\
\text { for } 50 \% \text { of the total area. }\end{array}$ & $30-10$ \\
\hline Extremely low & $\begin{array}{l}\text { Land productivity is completely lost, showing a complete wind- } \\
\text { or water-eroded desert landscape. }\end{array}$ & $<10$ \\
\hline
\end{tabular}

\subsection{Trend analysis and spatial comparison}

Time series of the averaged meteorological data from all sites in Qinghai and vegetation coverage data were used to determine whether interactions existed between them. Trend analysis models (e.g. mean value estimate, linear regression and exponential regression methods) were used to investigate the multi-year trends.

The annual mean air temperature, relative air humidity, wind speed and annual precipitation at 39 sites in Qinghai were used to represent Qinghai's annual climatic conditions. Linear regressions were used to analyze trends in precipitation, relative air humidity and wind speed during the period of 1961 to 2012, and an exponential regression was used to analyze air temperature trends. The area of vegetation coverage variation was used in temporal trend comparisons of vegetation coverage and climatic conditions.

The multi-year average climatic data from each meteorological station during the period of 1961 to 2012 were calculated and interpolated to raster images with a 1-km spatial resolution. Contours of climatic parameters were also constructed. Then, the spatial relationship between vegetation coverage and climatic variables was analyzed from 2000 to 2012.

\subsection{Correlation analysis and cross-classification}

Correlation coefficients between yearly assigned vegetation coverage values and annual averaged meteorological data from 39 sites from 2000 to 2012 were calculated using the Pearson correlation method. To identify the effects of climatic factors, we obtained a correlation matrix for the yearly vegetation coverage variation areas and annual climatic conditions using SPSS software.

\section{Results and discussion}

\subsection{Dynamic changes in vegetation coverage in Qinghai}

The area classified as extremely low vegetation coverage in Qinghai increased during the period of 2000 to 2012, with an average annual increase of $32.5 \mathrm{~km}^{2}\left(5.84 \%, R^{2}=0.7786, P<0.01\right)$ (Fig. 4a). This region is mainly distributed along the central line of the Qaidam Basin, indicating that Qinghai is still facing the risk of desertification. In contrast, the area classified as low vegetation coverage area decreased during the period of 2000 to 2012, with an average annual decrease of 2,091.8 $\mathrm{km}^{2}$ 
$\left(0.07 \%, R^{2}=0.4957, P<0.01\right)$ (Fig. 4b). The area classified as moderate vegetation coverage slightly increased, with an average annual increase of $1,868.3 \mathrm{~km}^{2}\left(R^{2}=0.3404, P<0.05\right)$ (Fig. 4c). The combined total area of extremely low and low vegetation coverage decreased, with an average annual decrease of $2,059.3 \mathrm{~km}^{2}(0.68 \%$ of the average extremely low vegetation coverage area during the period of 2000 to 2012) $\left(R^{2}=0.4884, P<0.01\right)$ (Fig. 4d). These data indicated that the spread of serious desertification in this province slowed during the period of 2000 to 2012. The total area classified as lower than moderate vegetation coverage $\left(5.4 \times 10^{5} \mathrm{~km}^{2}\right)$ did not significantly change during the period of 2000 to 2012, though it fluctuated annually (Fig. 4e).

The spatial distribution of extremely low and low vegetation coverage areas had no significant changes during the period of 2000 to 2012. Compared to 2000, the vegetation coverage slightly
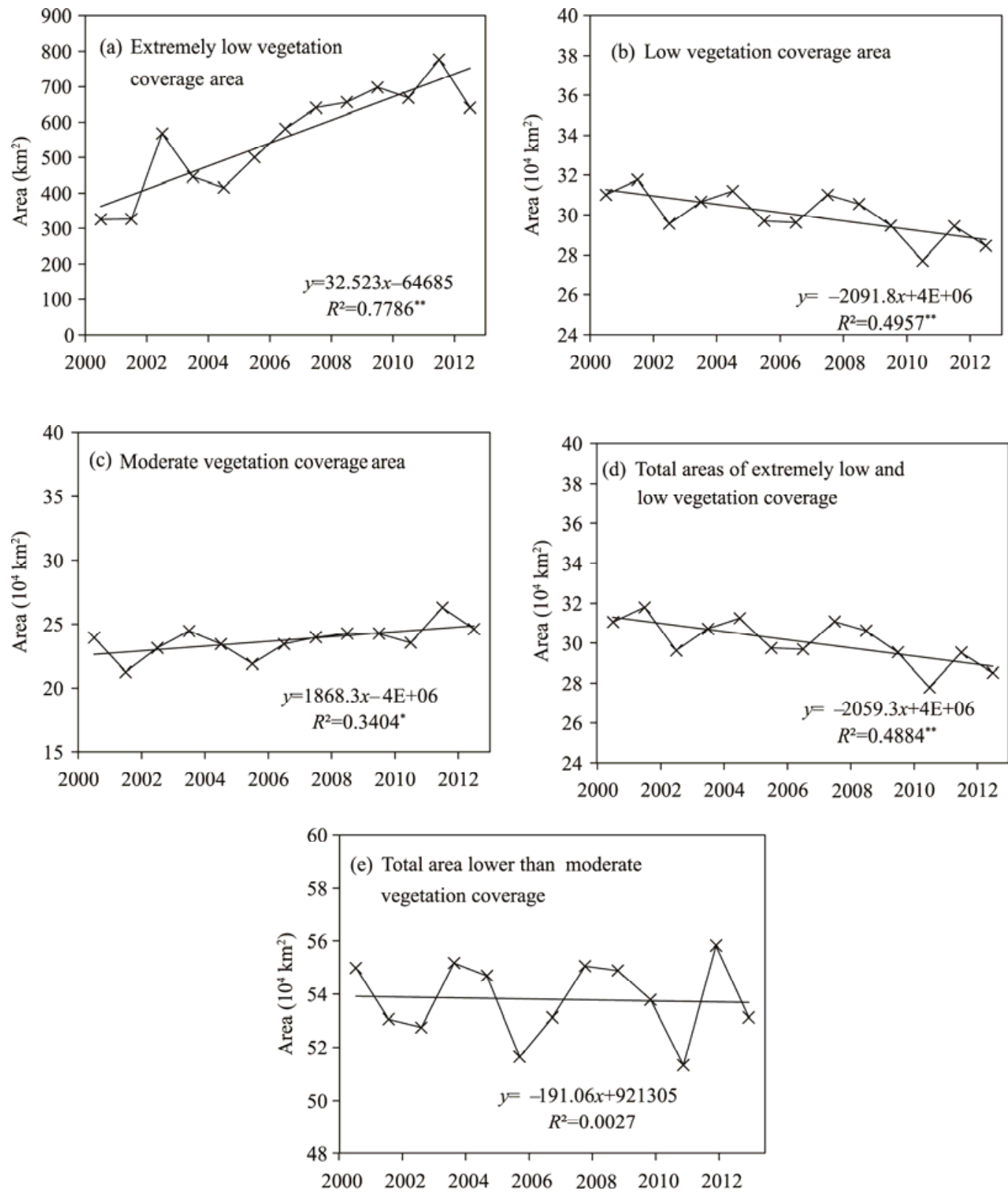

Fig. 4 Changes in vegetation coverage areas in Qinghai province. ${ }^{*}$ and ${ }^{* *}$ indicate significant differences at $P<0.05$ and $P<0.01$ levels, respectively. 
improved in southeastern Qinghai in 2006. However, the vegetation coverage decreased in southeastern Qinghai, especially on the northern shore of the Qinghai Lake in 2012. Generally, the vegetation coverage was low in most parts of Qinghai, especially in the Qaidam Basin and western mountain zone. The vegetation coverage in the southeastern Qinghai and northern shore of the Qinghai Lake was relatively higher than those in other regions. The differences in vegetation coverage during the period of 2000 to 2012 were used to analyze the spatial variation in vegetation coverage. The differences were divided into five levels (Fig. 5). Vegetation coverage decreased in southern and eastern Qinghai, where vegetation coverage was relatively higher than those in other regions. A decrease in vegetation coverage was obvious, especially in the Yellow River Basin, whereas the vegetation coverage increased in the southern Qinghai Lake.


Fig. 5 Spatial distribution of vegetation coverage and variations in vegetation coverage during the period of 2000 to 2012. (a)-(c) vegetation coverage in 2000, 2006 and 2012, respectively; (d) differences in vegetation coverage in 2012 compared to 2000. The results show the changes in vegetation coverage in 2012 compared to those in 2000 . Negative and positive values represent reduced vegetation coverage and increased vegetation coverage during the period of 2000 to 2012, respectively.

\subsection{Climatic characteristic and changes}

Using the observed meteorological data during the period of 1961 to 2012, the annual mean climatic data of all the meteorological stations in Qinghai were calculated to represent the climatic conditions (Fig. 6). The annual mean air temperature significantly increased over this period $\left(R^{2}=0.3834, P<0.01\right)$ from $0.5^{\circ} \mathrm{C}$ to $1.0^{\circ} \mathrm{C}$ between the $1960 \mathrm{~s}$ and $1980 \mathrm{~s}$ and from $1.0^{\circ} \mathrm{C}$ to $1.5^{\circ} \mathrm{C}$ between the 1980s and 2000 (Fig. 6a). The annual mean temperature significantly increased following an exponential trend during the 13 years since 2000.

The annual precipitation also increased over the 52-year period by an average of $0.7328 \mathrm{~mm} / \mathrm{a}$ $\left(R^{2}=0.0939, P<0.05\right)$ (Fig. 6b). However, the relative air humidity decreased $\left(R^{2}=0.1306, P<0.01\right)$ 
by an average of $0.0421 \%$ per year (Fig. 6c), indicating that the area was gradually getting drier, likely as a result of increased temperature. The annual mean wind speed increased from 1969 to 1974, and then gradually decreased by $2 \mathrm{~m} / \mathrm{s}\left(R^{2}=0.4680, P<0.01\right)$ (Fig. $\left.6 \mathrm{~d}\right)$. It is important to note that any decrease in wind speed would create an environment which is conducive to vegetation recovery and growth.
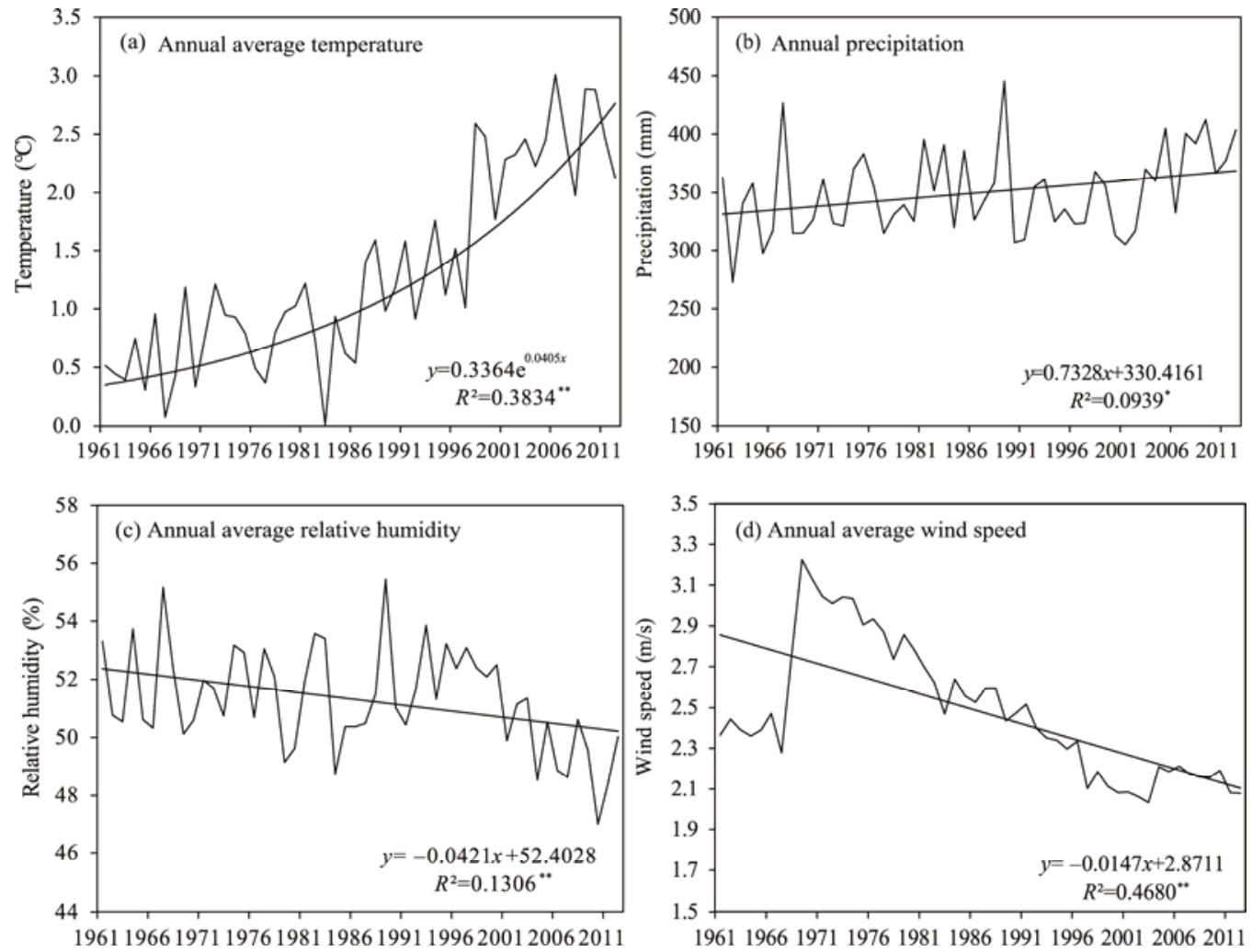

Fig. 6 Major climatic parameters and their trends in Qinghai province during the period of 1961 to 2012 . (a) annual mean air temperature; (b) mean annual precipitation; (c) annual mean relative air humidity; (d) annual mean wind speed. ${ }^{*}$ and ${ }^{* *}$ indicate significant differences at $P<0.05$ and $P<0.01$ levels, respectively.

\subsection{Influence of climate change on vegetation coverage}

The total areas of extremely low and low vegetation coverage in Qinghai were significantly and negatively correlated with the precipitation anomaly percentage, mean temperature and temperature anomalies $(P<0.05)$. Among these factors, the total extremely low and low vegetation coverage areas were most highly correlated with mean temperature $\left(R^{2}=-0.635\right)$, followed by precipitation anomalies $\left(R^{2}=-0.616\right)$. The correlation between the total extremely low and low vegetation coverage areas in Qinghai and the relative air humidity was not significant $\left(R^{2}=0.453\right)$. The relationship between climate and low vegetation coverage areas was complex, and it is difficult to clearly understand the relationship from only one climatic factor (Hulme and Kelly, 1993). However, increasing temperature and decreasing rainfall over long periods can cause dry land to become especially vulnerable to vegetation coverage (Amiraslani and Dragovich, 2011). Under harsh environments, reduced vegetation cover increases erosion due to runoff-generating rains, and thus contributes to desertification (Amiraslani and Dragovich, 2011). These changes are amplified when imbalances occur between the physical environment and human activities.

Although climate change will exacerbate vegetation coverage reduction through changes in temperature or rainfall, not all existing deserts will be equally affected (Sivakumar, 2007; Amiraslani and Dragovich, 2011). For example, temperature increases are not entirely detrimental 
to vegetation ecosystems (Glenn et al., 1998). Increased temperature can delay vegetation dormancy, thereby prolonging the growing season and reducing susceptibility to vegetation coverage reductions. This may explain why areas with low vegetation coverage in Qinghai have gradually diminished over the past 10 years. Therefore, obvious changes in the total areas of extremely low and low vegetation coverage in Qinghai were evidently correlated to temperature from 2000 to 2012 (Fig. 7). The total areas with extremely low and low vegetation coverage in Qinghai decreased in years with high average temperature but increased in years with low average temperature.



Fig. 7 Change in total areas of extremely low and low vegetation coverage and annual mean temperature during the period of 2000 to 2012 in Qinghai province

The spatial relationships between vegetation coverage and climatic factors were analyzed (Fig. 8). The spatial distributions of the different vegetation coverage classifications were consistent with the humidity and precipitation contour lines. Extremely low and low vegetation coverage regions were mostly distributed in areas with an annual mean relative air humidity of $<40 \%$, whereas moderate vegetation coverage regions were distributed in areas with an annual mean relative air humidity ranging between $40 \%-50 \%$. Regions with an annual mean relative air humidity of $>50 \%$ had relatively high vegetation coverage.

The spatial relationships between different vegetation coverage regions and precipitation are shown in Fig. 8b. The spatial distribution of extremely low and low vegetation areas was consistent with the 200 -mm precipitation contours, whereas moderate vegetation coverage areas were mainly distributed in regions with $<100 \mathrm{~mm}$ of precipitation. Regions with an annual precipitation of $200-$ $400 \mathrm{~mm}$ are considered as ecologically fragile areas (Wang et al., 2008), and are therefore the focus of vegetation protection measures to control improper human activities that exacerbate the risk of desertification. Areas with an annual precipitation of $>400 \mathrm{~mm}$ had a low risk of vegetation coverage reduction. Spatial relationships between vegetation coverage and multi-year mean temperature and wind speed were not obvious. However, it is important to note that high and low temperatures may increase the vulnerability of grassland ecosystems to desertification (Wang et al., 2008).

\subsection{Correlation between vegetation coverage and soil properties}

\subsubsection{Vegetation coverage area ratios}

Reductions in vegetation coverage are caused by the deterioration of the soil layer and the decline in or even disappearance of organic matter, which causes the land surface to become barren or compact. Soil type and soil texture in a certain area reflect the climate over geological history and the development of desertification. Soil type and soil texture affect the migration of water and salt in soil in various ways, as well as vegetation type and vegetation coverage (Liu et al., 2008). 

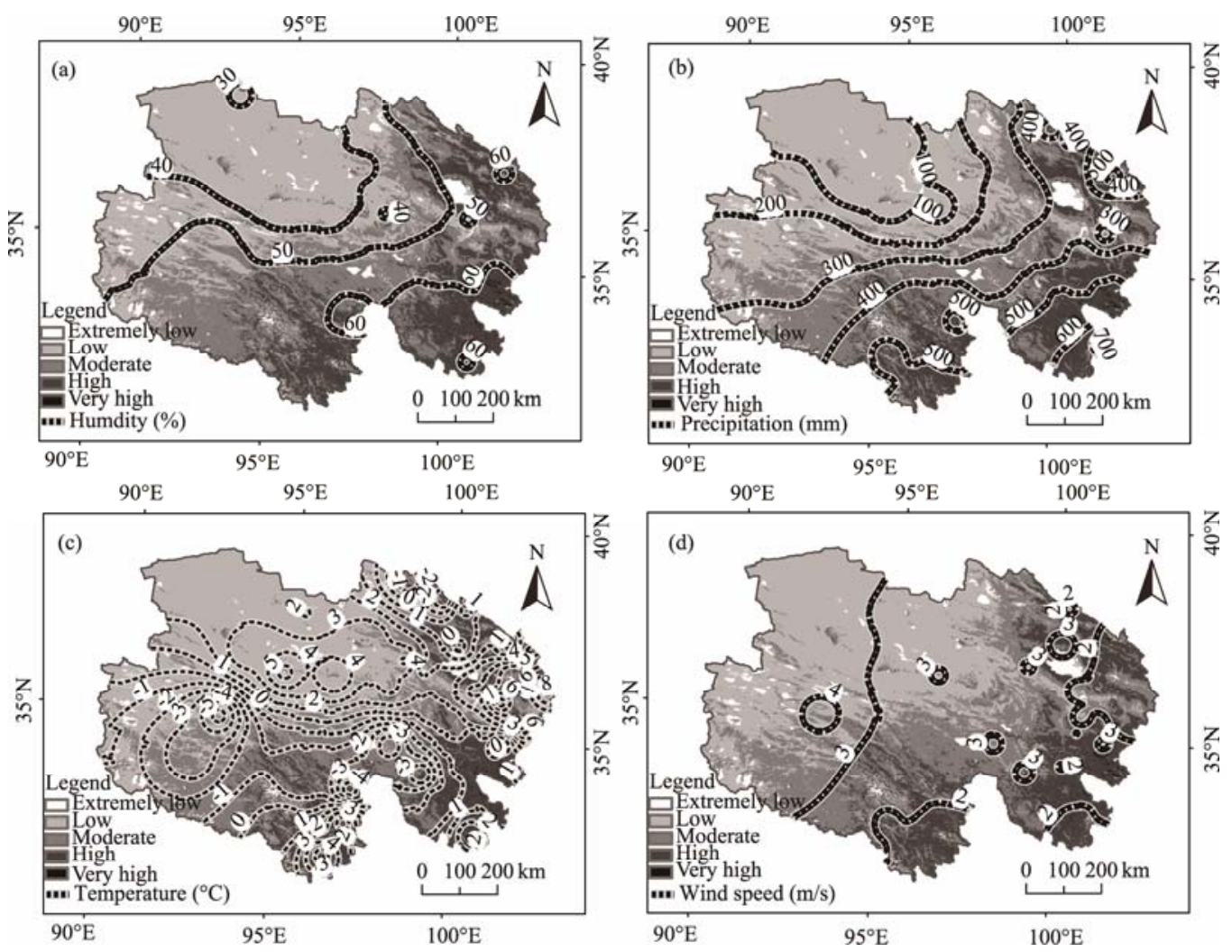

Fig. 8 Spatial relationships between average vegetation coverage (from 2000 to 2012) and multi-year mean climatic conditions. (a) vegetation coverage and multi-year mean relative humidity; (b) vegetation coverage and multi-year mean precipitation; (c) vegetation coverage and multi-year mean air temperature; (d) vegetation coverage and multi-year mean wind speed.

Vegetation coverage and area analyses can help to reveal the drivers of vegetation coverage change and the mechanisms of vegetation change processes in regions of various soil textures.

The vegetation coverage ratio represents the ratio of a vegetation coverage area to the total area of a certain soil type. The vegetation coverage ratios among different soil textures were significantly different (Table 2). The ratio of the total areas of extremely low and low vegetation coverage to the total areas of sandy clay loam soil was the largest (94.11\%). Qinghai has 3,614 $\mathrm{km}^{2}$ of total sandy clay loam soil areas, which are mainly distributed in the central region of Dulancounty. This area is surrounded by large areas of sand dunes and sand sheets, and therefore is susceptible to wind erosion. The ratio of the total areas of extremely low and low vegetation coverage to the total sandy loamy and sandy soil areas were large $(84.93 \%$ and $88.08 \%$, respectively). These two soils are primarily distributed in the Qaidam Basin and Chaka-Republic Basin, as well as to the north and east of Qinghai Lake. This area is the largest desertification region in Qinghai, with high wind speeds throughout most of the year. As such, the vegetation is relatively sparse. In addition, the soil texture and terrain factors increase the risk of vegetation coverage reduction in this area. Wind erosion and salinization alter the soil structure, which further exacerbates desertification. The total areas of extremely low and low vegetation coverage accounted for $72.57 \%$ of the total clay loam soil area and were mainly located in the central salt lake and oasis of the Qaidam Basin. Drought, evaporation and rich salt are natural conditions of saline desertification in this arid region, and evaporation causes salt accumulation on the land surface. Moreover, the river carries soluble salts into the lake and the river alluvial plain area, providing a source for salt accumulation in the soil. Within this soil type, high salinity and salt marshes easily cause reductions in vegetation coverage. 
Table 2 Percentages of extremely low and low vegetation coverage and moderate vegetation coverage areas to the total area of each soil type

\begin{tabular}{lcc}
\hline Soil texture & $\begin{array}{c}\text { Percentage of extremely low and } \\
\text { low vegetation coverage area (\%) }\end{array}$ & $\begin{array}{c}\text { Percentage of moderate vegetation } \\
\text { coverage area (\%) }\end{array}$ \\
\hline Water or other & 65.91 & 2.35 \\
Silty clay, silt soil & 52.12 & 33.86 \\
Clay & 28.24 & 45.56 \\
Silty clay loam & 9.12 & 54.61 \\
Clay loam & 72.57 & 23.55 \\
Silt loam & 1.16 & 34.87 \\
Loam & 39.99 & 33.14 \\
Sandy clay loam & 94.11 & 5.66 \\
Sandy loam & 34.46 & 43.12 \\
Loamy sand & 84.93 & 5.27 \\
Sand & 88.08 & 10.30 \\
\hline
\end{tabular}

Sandy loam and loam are the most widely distributed soils in Qinghai. In regions characterized by these two soils types, the ratios of the total areas of extremely low and low vegetation coverage were $34.46 \%$ and $39.99 \%$, respectively. Most agricultural regions are located on these types of soil, and vegetation coverage reduction in these areas is mainly due to overexploitation, except for in high altitude areas (Tian et al., 2013). Regions characterized by sandy loam and loam soils are also a focus for vegetation coverage reduction control efforts. Vegetation coverage reduction control can be achieved by active ecological engineering. However, if there is a lack of appropriate management measures, the environment will continue to be destroyed and vegetation coverage reduction and desertification will increase.

The percentages of the total areas of extremely low and low vegetation coverage to the total area of each soil type were different compared to the moderate vegetation coverage area percent. Sandy loam and loam soils in Qinghai have similar spatial distributions and are found in similar climatic conditions. However, the moderate vegetation coverage area percentages for these two soil types were $43.12 \%$ and $33.14 \%$, respectively. This indicates that soil texture is also a driver of vegetation coverage reduction under similar environmental conditions. Sandy loam soil has a greater sand content and permeability compared with loam soil and is more easily eroded by wind or water; thus, drought tolerant vegetation should be cultivated in these areas to prevent the risk of vegetation coverage reduction.

Clay and silt clay loam soils are mainly found in the central regions of the Qaidam Basin and Chaka Basin, where a harsh climate and high salt content create optimum conditions for vegetation coverage reduction. Areas with silt clay and silt loam soils are relatively small but widely distributed, primarily in the southern river valleys of the Qinghai and salt lake area. These two soils better support vegetation but are susceptible to salinization. Thus, they are still classified as having a high risk of vegetation coverage reduction.

\subsubsection{Multi-year vegetation coverage trends for each soil type}

The multi-year vegetation coverage area trends for each soil type are presented in Figs. 9 and 10. The most widely distributed soil types in Qinghai are sandy loam, loam and sand, with an area of $354,919,208,078$ and $49,197 \mathrm{~km}^{2}$, respectively. These three soil types also corresponded to the largest extremely low and low vegetation coverage areas, with the greatest area $\left(10^{4} \mathrm{~km}^{2}\right)$ corresponding to sandy loam soils, followed by loam $\left(8 \times 10^{4} \mathrm{~km}^{2}\right)$ and sand $\left(10^{4} \mathrm{~km}^{2}\right)$ soils.

The total areas of extremely low and low vegetation coverage in sandy loam soil regions showed obvious inter-annual variability. The smallest area of extremely low and low vegetation coverage was found in $2010\left(105,266 \mathrm{~km}^{2}\right)$, and the largest in $2001\left(132,474 \mathrm{~km}^{2}\right)$. The total extremely low 


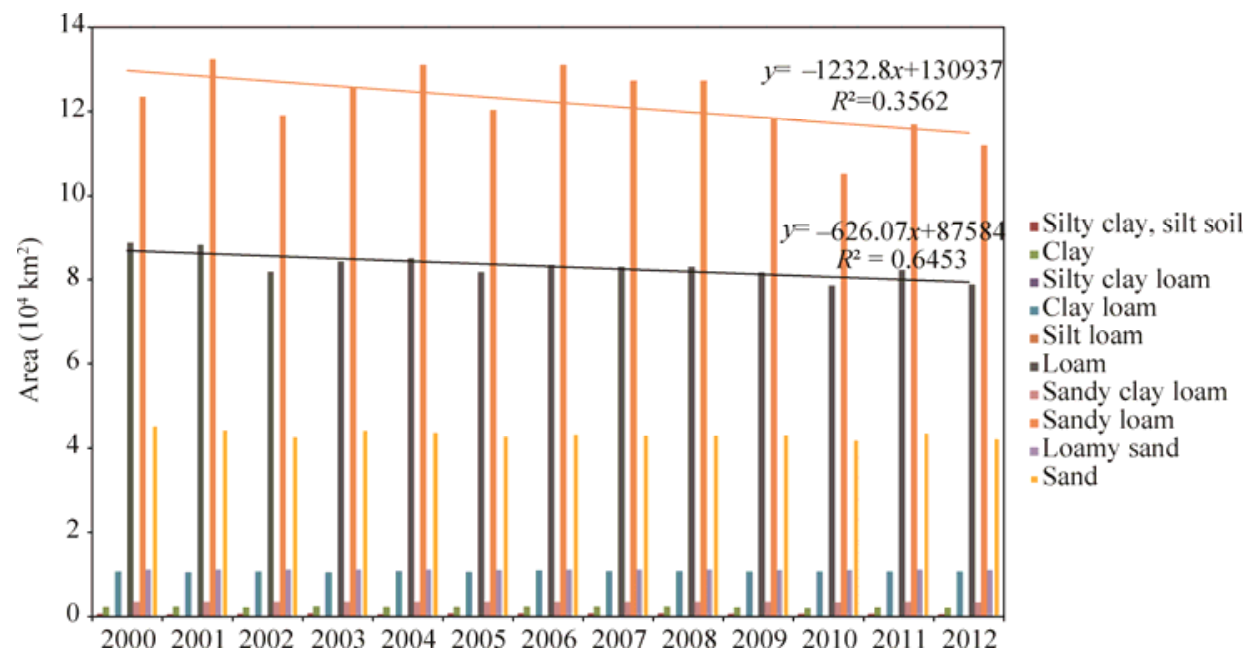

Fig. 9 Total extremely low and low vegetation coverage areas with various soil types in Qinghai province

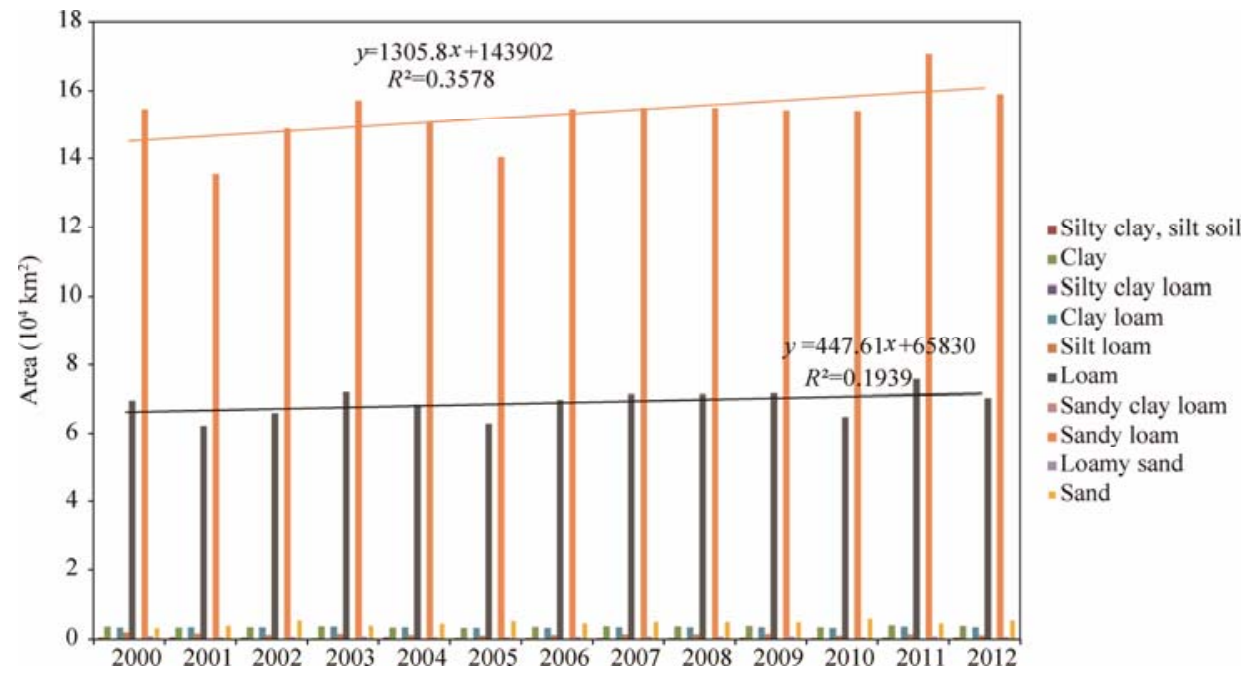

Fig. 10 Moderate vegetation coverage areas with various soil types in Qinghai province

and low vegetation coverage areas with sandy loam soil decreased by an average of $1,232.8 \mathrm{~km}^{2}$ annually $\left(R^{2}=0.3562\right)$. This indicates that the spread of vegetation coverage reduction in this province has slowed and agricultural land in Qinghai is increasing.

The inter-annual variation in the total extremely low and low vegetation coverage areas with loam soil slightly decreased $\left(R^{2}=0.6453\right)$, suggesting improvements in the environment. However, there was no obvious inter-annual variation in the total extremely low and low vegetation coverage areas with clay loam soil. Sand is mainly distributed in the Qaidam Basin and Chaka Basin, which primarily consist of dune and gravel and have low vegetation coverage. Thus, these regions have a risk of serious vegetation coverage reduction, though they are relatively stable with respect to desertification. Moderate vegetation coverage areas in regions with various soil types and their multi-year trends are presented in Fig. 8. Sandy loam and loam soil regions showed the highest risk of vegetation coverage reduction and corresponded to the largest moderate vegetation coverage areas $\left(15,000\right.$ and $7,000 \mathrm{~km}^{2}$, respectively). In contrast, the moderate vegetation coverage areas in regions with other soil types were small. The inter-annual variation in moderate vegetation coverage areas with sandy loam soil was significant; the largest of these areas $\left(170,692 \mathrm{~km}^{2}\right)$ was measured in 2011 and the smallest $\left(135,460 \mathrm{~km}^{2}\right)$ in 2001. A linear regression of the multi-year moderate vegetation coverage areas with sandy loam soil indicated the occurrence of a slow 
upward trend over the study period $\left(R^{2}=0.3578\right)$. Thus, the southern-most agricultural land in Qinghai still faces the risk of vegetation coverage reduction. These data suggest the need for continued efforts to reduce the risk of vegetation coverage reduction in this area. The vegetation coverage reduction risk in regions with loam soil was less compared with that in sandy loam soil regions. The inter-annual variation in moderate vegetation coverage areas with loam soil was small but exhibited a slow upward trend $\left(447.6 \mathrm{~km}^{2} / \mathrm{a} ; R^{2}=0.1939\right)$. Therefore, the risk of vegetation coverage reduction in farmland in Qinghai still exists.

\section{Conclusions}

This study investigated the trends of vegetation coverage in Qinghai in order to better understand the drivers of vegetation coverage variations. The results are summarized as follows:

(1) The area of extremely low vegetation coverage in Qinghai increased during the period of 2000 to 2012, with an average annual increase of $32.5 \mathrm{~km}^{2}$. Low vegetation coverage areas decreased by an average of 2,091.8 $\mathrm{km}^{2} /$ a. The spread of vegetation coverage reduction in this province has slowed, and the average annual reduction in the total areas of extremely low and low vegetation coverage was $2,059.3 \mathrm{~km}^{2}$.

(2) Annual mean temperature was the main climatic driver of the total extremely low and low vegetation coverage areas in Qinghai, followed by precipitation anomalies. Spatially, severe and serious desertification regions were almost completely distributed in areas with an average annual relative humidity of $<40 \%$, whereas moderate desertification areas were distributed in regions with an annual average relative humidity ranging from $40 \%$ to $50 \%$. The spatial distribution of desertification was consistent with the $200-\mathrm{mm}$ precipitation contours, and severe desertification occurred in areas with $<100 \mathrm{~mm}$ of precipitation.

(3) Sandy clay loam soil was the main soil driver of vegetation coverage, followed by loamy sand and sandy soil properties. Regions with sandy loam and loam soils showed the highest risk of vegetation coverage reduction. Soil texture was also a driver of vegetation coverage variations under similar climatic conditions. Soils with a large particle size had high permeability and were easily influenced by water and soil erosion, and therefore displayed a high vegetation coverage reduction risk.

Changes in vegetation coverage have an important influence on energy and biological chemical cycles. The investigation of vegetation coverage variations and its natural drivers is important to understanding the effects of global environmental change. Vegetation coverage is also an effective indicator of land deterioration, salinization and desertification. Research on vegetation coverage in the ecological fragile region of Qinghai can provide a scientific reference and management support for coping with environmental change and desertification.

\section{Acknowledgements}

This work was supported by the Important Science \& Technology Specific Projects of Qinghai Province (2014-NKA4-1), and the Special Funds for Public Industry Research Projects of Ministry of Water Resources of China (201301009). The authors would like to thank JIA Ruijing for her helpful editorial support and the reviewers of the manuscript for their helpful comments. We are also grateful to the Level 1 and Atmosphere Archive and Distribution System and China Meteorological Data Sharing Service System for providing the remote sensed and meteorological data to support our research.

\section{References}

Amiraslani F, Dragovich D. 2011. Combating desertification in Iran over the last 50 years: An overview of changing approaches. Journal of Environmental Management, 92(1): 1-13.

Bonan G. 2002. Ecological Climatology: Concepts and Applications. Cambrige: Cambridge University Press.

Burke E J, Brown S J, Christidis N. 2006. Modeling the recent evolution of global drought and projections for the twenty-first century with the hadley centre climate model. Journal of Hydrometeorology, 7(5): 1113-1125. 
CMB (China Meteorological Bureau). 2003. Ground Surface Meteorological Observation Protocols. Beijing: China Meteorological Bureau Press, 151. (in Chinese)

Dai A G. 2011. Drought under global warming: a review. Wiley Interdisciplinary Reviews: Climate Change, 2(1): $45-65$.

Ding G D, Zhao T Y, Fan J Y, et al. 2004. Analysis on development of desertification assessment indicator system. Journal of Beijing Forestry University, 26(1): 92-96. (in Chinese)

D’Odorico P, Caylor K, Okin G S, et al. 2007. On soil moisture-vegetation feedbacks and their possible effects on the dynamics of dryland ecosystems. Journal of Geophysical Research: Biogeosciences, 112(G4): G04010.

D’Odorico P, Bhattachan A, Davis K F, et al. 2013. Global desertification: drivers and feedbacks. Advances in Water Resources, 51: 326-344.

Friedl M A, McIver D K, Hodges J C F, et al. 2002. Global land cover mapping from MODIS: algorithms and early results. Remote Sensing of Environment, 83(1-2): 287-302.

Friedl M A, Sulla-Menashe D, Tan B, et al. 2010. MODIS collection 5 global land cover: algorithm refinements and characterization of new datasets. Remote Sensing of Environment, 114(1): 168-182.

Glenn E, Stafford Smith M, Squires V. 1998. On our failure to control desertification: implications for global change issues, and a research agenda for the future. Environmental Science \& Policy, 1(2): 71-78.

Goudie A S. 2006. The history and evolution of desert hydrology and landforms: the role of climate change. In: D’Odorico P, Porporato A. Dryland Ecohydrology. New York: Springer, 129-140.

Guo W, Ni X N, Jing D Y, et al. 2014. Spatial-temporal patterns of vegetation dynamics and their relationships to climate variations in Qinghai Lake Basin using MODIS time-series data. Journal of Geographical Sciences, 24(6): 1009-1021.

Gutman G, Ignatov A. 1998. The derivation of the green vegetation fraction from NOAA/AVHRR data for use in numerical weather prediction models. International Journal of Remote Sensing, 19(8): 1533-1543.

He Z, He J P. 2011. Desertification monitoring of loess plateau based on MODIS. Remote Sensing Technology and Application, 26(4): 476-481. (in Chinese)

Hou G L, Yang P, Cao G C, et al. 2015. Vegetation evolution and human expansion on the Qinghai-Tibet Plateau since the Last Deglaciation. Quaternary International, doi: 10.1016/j.quaint.2015.03.035.

Huang Y Z, Wang N A, He T H, et al. 2009. Historical desertification of the Mu Us Desert, Northern China: a multidisciplinary study. Geomorphology, 110(3-4): 108-117.

Hulme M, Kelly M. 1993. Exploring the links between desertification and climate change. Environment: Science and Policy for Sustainable Development, 35(6): 4-11, 39-45.

IPCC (Intergovernmental Panel on Climate Change). 2007. Climate Change 2007: Working Group I: The Physical Science Basis. In: Solomon S, Qin D, Manning M, et al. Contribution of Working Group I to the Fourth Assessment Report of the Intergovernmental Panel on Climate Change. United Kingdom and New York: Cambridge Press, 1-23.

Kim D W, Byun H R. 2009. Future pattern of Asian drought under global warming scenario. Theoretical and Applied Climatology, 98(1-2): 137-150.

Liberti M, Simoniello T, Carone M T, et al. 2009. Mapping badland areas using LANDSAT TM/ETM satellite imagery and morphological data. Geomorphology, 106(3-4): 333-343.

Liu Q S, Liu G H, Zhao J. 2008. The indication function of soil type and soil texture and land type to soil salinization levels. Chinese Agriculture Science Bulletin, 24(1): 297-300. (in Chinese)

Maas S J. 1998. Estimating cotton canopy ground cover from remotely sensed scene reflectance. Agronomy Journal, 90(3): 384388.

MEA (Millennium Ecosystem Assessment). 2005. Ecosystems and Human Well-Being: Desertification Synthesis. Washington DC: World Resource Institute.

Mu S J, Li J L, Chen Y Z, et al. 2012. Spatial differences of variations of vegetation coverage in inner mongolia during 2001-2010. Acta Geographica Sinica, 67(9): 1255-1268. (in Chinese)

Pan X P, Wu X F, Shen Y J, et al. 2015. Responses of vegetation coverage changes to climate factors in the source regions of three parallel rivers. Mountain Research, 33(2): 218-226. (in Chinese)

Peng J, Liu Z H, Liu Y H, et al. 2012. Trend analysis of vegetation dynamics in Qinghai-Tibet Plateau using Hurst Exponent. Ecological Indicators, 14(1): 28-39.

Qi J, Marsett R C, Moran M S, et al. 2000. Spatial and temporal dynamics of vegetation in the San Pedro River basin area. Agricultural and Forest Meteorology, 105(1-3): 55-68.

Qi Y B, Chang Q R, Jia K L, et al. 2012. Temporal-spatial variability of desertification in an agro-pastoral transitional zone of 
northern Shaanxi Province, China. Catena, 88(1): 37-45.

Qin Y, Yi S H, Chen J J, et al. 2015. Effects of gravel on soil and vegetation properties of alpine grassland on the Qinghai-Tibetan plateau. Ecological Engineering, 74: 351-355.

Runnström M C. 2003. Rangeland development of the Mu Us Sandy Land in semiarid China: an analysis using Landsat and NOAA remote sensing data. Land Degradation \& Development, 14(2): 189-202.

Sheffield J, Andreadis K M, Wood E F, et al. 2009. Global and continental drought in the second half of the twentieth century: severity-area-duration analysis and temporal variability of large-scale events. Journal of Climate, 22(8): 1962-1981.

Sivakumar M V K. 2007. Interactions between climate and desertification. Agricultural and Forest Meteorology, 142(2-4): 143155.

Sun H Y, Wang C Y, Niu Z, et al. 1998. Analysis of vegetation cover change and the relationship between NDVI and environmental factors by using NOAA time series data. Journal of Remote Sensing, 2(3): 204-210. (in Chinese)

Taylor C M, Lebel T. 1998. Observational evidence of persistent convective-scale rainfall patterns. Monthly Weather Review, 126(6): 1597-1607.

Taylor C M, Saïd F, Lebel T. 1997. Interactions between the land surface and mesoscale rainfall variability during HAPEX-Sahel. Monthly Weather Review, 125(9): 2211-2227.

Tian L H, Zhang D S, Hu M J, et al. 2013. Driving forces of land Aeolian desertification in Gangcha county of Qinghai Province, China, during 1976-2007. Journal of Desert Research, 33(2): 493-500. (in Chinese)

USDA (United States Department of Agriculture). 2008. Natural Resources Conservation Service (NRCS). http://www.usda.gov/wps/portal/usda/usdahome?contentid=NRCS_Agency_Splash.xml\&contentidonly=true.

Wang G X, Liu G S, Li C J, et al. 2012. The variability of soil thermal and hydrological dynamics with vegetation cover in a permafrost region. Agricultural and Forest Meteorology, 162-163: 44-57.

Wang J, Li W J, Song D M, et al. 2004. The analysis of land desertification changing of Minqin county in recent 30 years. Journal of Remote Sensing, 8(3): 282-288. (in Chinese)

Wang X M, Chen F H, Hasi E, et al. 2008. Desertification in China: an assessment. Earth-Science Reviews, 88(3-4): 188-206.

Wang Z X, Liu C, Chen W B, et al. 2006. Preliminary comparison of MODIS-NDVI and MODIS-EVI in Eastern Asia. Geomatics and Information Science of Wuhan University, 31(5): 407-427. (in Chinese)

Yan C Z, Wang T, Han Z W, et al. 2007. Surveying sandy deserts and desertified lands in north-western China by remote sensing. International Journal of Remote Sensing, 28(16): 3603-3618.

Yan C Z, Song X, Zhou Y M, et al. 2009. Assessment of Aeolian desertification trends from 1975's to 2005's in the watershed of the Longyangxia Reservoir in the upper reaches of China's Yellow River. Geomorphology, 112(3-4): 205-211.

Yu H Y, Zhang Z D, Zhang P M. 2007. RS-and GIS-based evaluation and dynamic monitoring of land desertification in Qinghai province. Arid Zone Research, 24(2): 153-158. (in Chinese)

Zeng X B, Dickinson R E, Walker A, et al. 2000. Derivation and evaluation of global 1-km fractional vegetation cover data for land modeling. Journal of Applied Meteorology, 39(6): 826.

Zhang X B, Zwiers F W, Hegerl G C, et al. 2007. Detection of human influence on twentieth-century precipitation trends. Nature, 448(7152): 461-465. 